\title{
Migrantes deportados: entre la concepción de los desechos humanos y la de los derechos humanos
}

\author{
Joaquin A. Mejia R.
}

\section{Recibido: octubre de 2010 / Aceptado: enero de 2011}

La crisis económica mundial está provocando una crisis de los valores democráticos en las sociedades del Norte cuando se trata de abordar el fenómeno migratorio. Cada vez más los Estados de Europa y Estados Unidos ven en la migración un asunto que se desecha cuando ya no es útil ni rentable y los derechos humanos de los inmigrantes son sacrificados en el altar de la seguridad nacional, del orden público y de la recesión económica. De esta manera, en nombre de su soberanía, los Estados aplican políticas migratorias que atentan contra los derechos de las poblaciones migrantes sujetas a deportación, negándoles el derecho básico a ser oído por un juez independiente e imparcial. El objetivo de este artículo es mostrar que cuando un Estado falla en su obligación de respetar y garantizar los derechos humanos, se pueden activar los sistemas de protección internacional para revertir decisiones estatales que responden a una política migratoria discriminatoria y contraria a la dignidad humana.

Palabras clave: migración / deportaciones / Sistema Interamericano de Derechos Humanos / política migratoria 


\section{Los inmigrantes en tiempos hostiles}

Son tiempos hostiles para las migraciones, sobre todo para la indocumentada, la "ilegal". Desde Estados Unidos hasta Europa corren vientos de desprecio contra los inmigrantes, a quienes se les asocia con la violencia, el miedo, la inseguridad, la crisis económica, el desempleo y el deterioro de los servicios públicos.

En el pasado reciente los inmigrantes eran indudablemente necesarios porque contribuían al desarrollo económico de los países receptores. Pero hoy, en el imaginario colectivo de las sociedades del Norte -alimentado por sus gobiernos-su presencia es culpable de todas las desgracias, de todas las crisis. De este modo, el inmigrante se ha convertido en la víctima expiatoria de todos los males y para él, han llegado "los tiempos del desprecio" (Naïr, 2006, p.15). Estos "tiempos del desprecio" se manifiestan en las políticas de sospecha contra el que es "diferente", contra el "otro", contra quien no es parte del "nosotros", lo cual alimenta la arrogancia, el racismo y la xenofobia que terminan criminalizando la inmigración. La falta de un documento, de una visa o de una tarjeta de residencia se convierte en ilegalidad, en delito que debe ser situado y tratado al mismo nivel que el narcotráfico y el terrorismo.

Pero en estos tiempos ni siquiera el inmigrante documentado está a salvo pues aunque porta un papel que le confiere un estatus superior al que no lo tiene, sigue siendo visto como uno de los enemigos de turno que la ofensiva neoliberal ha creado para desviar la atención de las verdaderas causas de la actual crisis económica, social, política y cultural, "orientando los impulsos emotivos de las masas hacia formas regresivas y autoritarias de identificación” (Barcellona, 1992, p.24). Por esta razón, no es de extrañar que si el inmigrante comete un error, por muy pequeño que sea (una infracción de tráfico, por ejemplo), puede ser doblemente sancionado con una condena administrativa, civil o penal y luego, deportado.

Bajo estos parámetros no es de extrañar entonces que desde la Europa "democrática y respetuosa de los derechos humanos", en donde viven aproximadamente 8 millones de inmigrantes indocumentados, el Parlamento Europeo haya aprobado la llamada "Directiva de retorno sobre inmigración ilegal" que (a) permite la detención administrativa del indocumentado hasta un año y medio mientras se tramita su expulsión; (b) prohíbe a los deportados su ingreso a cualquiera de los 27 Estados miembros durante cinco años; y (c) faculta la expulsión de niños y niñas inmigrantes no acompañados a su país de origen o a un tercer país que no sea el suyo (Comisión de las Comunidades Europeas, 2005). Estas y otras medidas abiertamente violan los derechos humanos de los inmigrantes.

De la misma manera, Estados Unidos ha adoptado políticas migratorias que en vez de detener los flujos migratorios sólo han logrado criminalizarlos. Esto se refleja en el despliegue de los Minutemen con la tolerancia de las autoridades estadounidenses y el apoyo público mostrado por algunas autoridades políticas; el envío a la frontera de nuevos agentes de la patrulla fronteriza a la que además se le ha dotado de aviones y helicópteros militares; la construcción y ampliación de muros fronterizos con la participación del ejército; la estrecha colaboración entre la policía y las fuerzas militares en el control de la frontera; y el uso de detectores electrónicos 
de movimiento, proyectores potentes, telescopios infrarrojos o cables electrónicos (Nair, 2006, pp. 75-78).

A ello se le suma la adopción de leyes discriminatorias como la Proposition 187, la Ley de Protección al Contribuyente de California, la Ley de Antiterrorismo y de Pena de Muerte Efectiva (AEDPA, por sus siglas en inglés) o la reciente Ley 1070 conocida como "Ley de Arizona"; todo lo cual se traduce en la posibilidad de cancelar la ciudadanía que facilita la deportación; las redadas y detenciones masivas en hogares y centros de trabajo; y el aumento en el número de deportaciones de inmigrantes que, de acuerdo con el director de la Agencia de Inmigración y Aduanas (ICE, por sus siglas en inglés), alcanzó en el último año fiscal la cifra sin precedentes de 380.000, de los cuales casi un tercio habían sido declarados culpables por la comisión de un delito (AOL Noticias, 2010).

De esta manera, en el marco de la crisis económica mundial, los Estados del Norte están abordando el fenómeno migratorio alejándose cada vez más de una concepción basada en los derechos humanos y acercándose a una concepción de los desechos humanos en virtud de la cual los "migrantes son residuos humanos en sus países de origen y luego, como deportados, se convierten en residuos de los países de destino" (Rocha, 2008).

¿Qué hacer ante esta realidad en la que los Estados apelan a su soberanía para aplicar políticas migratorias que atentan contra los derechos humanos de las poblaciones migrantes sujetas a deportación? En el presente artículo se pretende presentar a grandes rasgos el escenario en el que los Estados adoptan medidas migratorias incompatibles con las normas internacionales que se han comprometido a cumplir -existe la posibilidad de presentar denuncias ante ciertos órganos supraestatales para revertir tal situación-. Concretamente, en el artículo se analiza el papel de la Comisión Interamericana de Derechos Humanos (en adelante la CIDH) y sus resoluciones en algunos casos de deportación realizados por Estados Unidos, de las cuales se pueden extraer algunos elementos esenciales que debe tener toda política migratoria basada en una concepción de los derechos humanos.

\section{De las estadísticas a la tragedia humana de las deportaciones}

Antes de 1996 los jueces estadounidenses de inmigración tenían discrecionalidad para sopesar algunos factores antes de ordenar la deportación de una persona que hubiera cometido algún delito, tales como, los vínculos familiares, la edad en que llegó al país y el tiempo que había estado en él, el impacto de su deportación en sus familiares, y la gravedad del delito que llevó al caso de deportación y su posible rehabilitación. En este sentido, en el marco de la Inmigration and Nationality Act (INA), el artículo 244 permitía la suspensión de la deportación de no ciudadanos de buena moral que hubieran vivido en los Estados Unidos por un mínimo de siete años, y cuya deportación provocaría dificultades extremas a ellos o a sus cónyuges, padres o hijos con residencia legal en el país. Esta normativa fue sustituida en 1996 por el artículo 240A (a) de la Ley de Reforma de la Inmigración y Responsabilidad 
del Inmigrante (IIRIRA, por sus siglas en inglés) que sólo puede ser invocada por residentes legales declarados culpables de una categoría específica de delitos, que hayan residido en los Estados Unidos por un mínimo de siete años y cuya rehabilitación y lazos con el país hagan que su estadía sea de interés nacional (Human Rights Watch, 2009, pp. 16-17).

A su vez, el Congreso estadounidense eliminó por completo el artículo 212 (c) que permitía a los residentes permanentes sujetos de deportación demostrar que factores positivos como sus lazos familiares y la evidencia de su rehabilitación, compensaban los factores negativos como la gravedad de sus actos delictivos para no ser deportados. En términos generales, la IIRIRA y AEDPA de 1996 (a) eliminaron todas las formas de reparación discrecional para residentes legales condenados por un delito grave; (b) expandieron la definición de gravedad para incluir algunos delitos relativamente menores; y (c) eliminaron la discreción que tenían los tribunales de dispensar la deportación por razones humanitarias y otras consideraciones (Human Rights Watch, 2009, pp. 17-18).

Lo anteriormente planteado es una pequeña muestra de cómo importantes disposiciones de las leyes migratorias en Estados Unidos son contrarias a las normas internacionales de derechos humanos que exige que los Estados respeten las garantías esenciales de un juicio justo en las audiencias de deportación.

Evidentemente, si con estas reformas la situación de los inmigrantes documentados se ha vuelto más vulnerable, la de los que se encuentran en situación irregular ha alcanzado el nivel de una verdadera tragedia humana para ellos y sus familias. Sólo basta echar un vistazo a las estadísticas que nos muestran que hay alrededor de 5.5 millones de niños y niñas -cerca de los cuales tres cuartas partes son ciudadanos nacidos en Estados Unidos- cuyos padres y madres son inmigrantes indocumentados, y que el gobierno federal estadounidense ha invertido billones de dólares cada año para arrestarlos, detenerlos y deportarlos. De hecho, se estima que en los últimos 10 años aproximadamente 100 mil inmigrantes padres y madres de niños y niñas estadounidenses han sido deportados ${ }^{1}$.

\section{Wayne Smith y Hugo Armendáriz: dos historias, 100 mil reflejos ${ }^{2}$}

Los 100 mil padres y madres que han sido deportados en los últimos 10 años tienen nombres y apellidos, historias personales y vinculaciones familiares, culturales, sociales, económicas, etc., que hacen de la deportación una verdadera tragedia humana para las familias que las sufren. Este es el caso de Wayne Smith y Hugo Armendáriz, el primero nacido en Trinidad y Tobago, y el segundo en México, cuyas historias representan el calvario que viven la mayoría de deportados y sus familiares

\footnotetext{
1 Sobre el efecto de las redadas migratorias sobre los niños y niñas de los inmigrantes detenidos y deportados, véase Chaudry et al. (2010). En Europa, Francia ha ido aún más lejos al ordenar -mediante un decreto presidencial- la expulsión de niños y niñas nacidas en Francia de padres indocumentados.

2 La información aqui compartida ha sido recopilada de Comisión Interamericana de Derechos Humanos / Organización de los Estados Americanos [CIDH] (2010, 12 de julio, párr. 12-21).
} 
cuando se enfrentan a un Estado que en nombre de la seguridad pública adopta medidas que atentan contra la vida privada y familiar, la integridad, la libertad y la justicia.

\subsection{La familia Smith/Hoyte}

Wayne Smith inmigró junto con sus padres a Estados Unidos en 1967 cuando tenía 10 años de edad y en 1974 se convirtió en residente legal permanente. En febrero de 1990 fue acusado de posesión de cocaína e intento de distribución, por lo que cumplió una condena de tres años de prisión en una penitenciaría estatal. Después de ser puesto en libertad, continuó prestando servicios religiosos voluntarios en la cárcel, y trabajó como consejero en cuestiones de drogas, participó en programas de la comunidad y completó sus estudios universitarios.

En 1996 contrajo matrimonio con Ann Hoyte, una ciudadana estadounidense con quien tiene una hija estadounidense, Karina Ann, la que se suma a dos hijas mayores de una relación anterior y que también viven en Estados Unidos. Junto con su esposa, iniciaron una pequeña empresa de limpieza en la que han contratado a más de quince personas, la mayoría en recuperación de adicción a las drogas. Además, compraron una casa familiar y han cumplido puntualmente sus obligaciones ciudadanas.

En marzo de ese año las autoridades migratorias iniciaron un procedimiento contra Wayne Smith que podría acabar en deportación, pero como aún no se había aprobado la IIRIRA y la AEDPA, él era elegible para que se le aplicara el artículo 212 (c) que suspendería la deportación por razones humanitarias, teniendo en cuenta sus vínculos familiares en los Estados Unidos, el período de residencia, especialmente si el inicio de la residencia comenzó a muy temprana edad, las penurias de la familia que dejaría en el país, los servicios prestados a la comunidad y cualquier otra evidencia de rehabilitación social y buena conducta.

No obstante, al momento en que la corte de inmigración conoció su caso, ya se habían aprobado la AEDPA y la IIRIRA, por lo que el juez dictó una sentencia que estipulaba su deportación sin tomar en cuenta el artículo 212(c). Aunque Wayne Smith apeló la sentencia y presentó una solicitud de habeas corpus ante la Corte Federal de Estados Unidos, ambos recursos fueron denegados y finalmente fue deportado a Trinidad y Tobago en diciembre de 1998.

En enero de 1999 Smith reingresó a Estados Unidos para continuar residiendo con su familia pero en marzo de 2001 fue detenido por la policía por una infracción de tráfico, fue entregado a las autoridades migratorias, detenido en la cárcel sin fianza, le fue denegada la posibilidad de ser escuchado en una audiencia por un juez de inmigración y finalmente, fue deportado nuevamente el 13 de diciembre de 2001.

\subsection{La familia Armendáriz/Porter}

En 1972, cuando Hugo Armendáriz tenía dos años de edad, inmigró junto con sus padres a los Estados Unidos. Seis años más tarde obtuvo su residencia legal permanente; por tanto, ha residido en el país prácticamente toda su vida, con 
excepción de sus primeros dos años. En 1994 se casó con Natalie Porter, compraron una casa en la que han vivido junto con su hijastra y con su hija adolescente, ambas nacidas en los Estados Unidos.

Como familia tienen un negocio exitoso y pagan todos sus impuestos. Muchos miembros de su familia inmediata son ciudadanos estadounidenses y en este sentido, Hugo Armendáriz no tiene familiares cercanos que vivan en México ni vínculos significativos con ese país ya que, entre otras cosas, no lee ni escribe en español.

En septiembre de 1995, Armendáriz fue condenado por un jurado por posesión de cocaína para la venta y por obstaculizar el juicio. En abril de 1996 cuando estaba cumpliendo su sentencia en un campo de trabajo de seguridad mínima, las autoridades migratorias expidieron una orden judicial en la que establecían que se le podía deportar como una persona condenada por un delito grave, a pesar de que en el momento que se libró tal orden, Hugo Armendáriz era elegible para recibir una dispensa de deportación por razones humanitarias, de conformidad con el referido artículo 212(c).

Ante tales hechos, Armendáriz presentó una solicitud de dispensa pero al momento en que un juez de inmigración dictó sentencia sobre su solicitud en abril de 1997, ya se había promulgado la AEDPA y la IIRIRA, y de esta manera se había eliminado el artículo 212(c) que podría suspender su deportación por razones humanitarias. Como consecuencia, el 16 de abril de 1997, el juez de inmigración dispuso su deportación, y a pesar de que fue apelada y presentada una solicitud de habeas corpus, ambas fueron denegadas por las autoridades correspondientes y por tanto, se ratificó su deportación a México en junio de 2003.

En ambas historias, la deportación ha tenido un evidente impacto nocivo en ellos y sus familiares, y para sus hijos e hijas ha significado la pérdida del apoyo moral y emocional de sus padres. En el caso de Wayne Smith, su esposa, que es una sobreviviente de cáncer de mama que necesita tratamiento de radiación y un monitoreo continuo, y que ha perdido su seguro de salud, la deportación la ha privado del aporte material de su esposo, y ha tenido que luchar sola por mantener a su hija y pagar los costos básicos para subsistir.

\section{El derecho contra el derecho: leyes migratorias y derecho internacional de los derechos humanos}

Frente a estos actos estatales que, aunque se revisten de legalidad en el ámbito interno vulneran normas básicas de derechos humanos reconocidas en el ámbito internacional, la pregunta que surge es ¿qué hacer?, ¿qué posibilidades tienen las víctimas de este tipo de deportaciones de cuestionar la legalidad de las mismas cuando los propios Estados han cerrado las puertas de la justicia a nivel nacional?

Ante todo, es preciso señalar que la irrupción de los derechos humanos en el marco político-jurídico contemporáneo ha permitido que el principio de soberanía ya no sea concebido de forma absoluta en el sentido de que la violación a tales derechos dentro de un territorio no constituye sólo una cuestión de alcance nacional 
sino un asunto que compete a toda la comunidad internacional. Teniendo en cuenta esta nueva realidad, la comunidad internacional se ha organizado de tal manera que ha creado sistemas de protección para darle plena efectividad a los derechos humanos cuando los Estados fallan en ello.

Estos sistemas de protección pueden ser de tipo universal y regional. En el primer tipo se encuentra el sistema de las Naciones Unidas y en el segundo, el Sistema Interamericano, el sistema europeo y el sistema africano de derechos humanos. Así, cada uno de estos sistemas de protección se ha dotado de dos componentes esenciales: (a) los instrumentos de protección, que son el marco normativo donde se reconoce los derechos humanos que los Estados se comprometen a garantizar dentro de sus respectivas jurisdicciones ${ }^{3}$; y (b) los mecanismos de protección, que son los órganos creados -generalmente por los mismos tratados- para que vigilen el cumplimiento de las obligaciones establecidas en esos instrumentos.

En los casos que nos ocupan, nos interesa el Sistema Interamericano, el cual está constituido por una serie de instrumentos de protección encabezados por la Carta de la OEA que proclama los "derechos fundamentales de la persona humana" como uno de los principios en que se funda la organización; la Declaración Americana de Derechos y Deberes del Hombre ${ }^{4}$ (en adelante la Declaración Americana); la Convención Americana sobre Derechos Humanos (en adelante el Pacto de San José); y otros instrumentos de carácter más específico relacionados con la abolición de la pena de muerte, los derechos económicos, sociales y culturales, la prevención y sanción de la tortura, la prevención, sanción y erradicación de la violencia contra la mujer, entre otros.

A su vez, existen dos órganos especiales encargados de vigilar el cumplimiento de los derechos reconocidos en tales instrumentos: la CIDH y la Corte Interamericana de Derechos Humanos (en adelante la Corte IDH), que aunque tienen un carácter coadyuvante o complementario respecto del derecho y órganos internos de los Estados americanos, pueden examinar los actos u omisiones de los distintos órganos estatales para verificar su conformidad con las obligaciones internacionales en materia de derechos humanos (Cançado Trindade, 2001, p. 274). Pero para esto es necesario que las víctimas observen la regla del agotamiento de los recursos internos, la cual se basa en el principio de que un Estado denunciado debe estar en condiciones de brindar una reparación por sí mismo y dentro del marco de su sistema jurídico interno.

Dentro del Sistema Interamericano existen tres niveles de protección referidos al grado de compromiso asumido por los Estados. Así, (a) hay algunos Estados que sólo son signatarios de la Declaración Americana y respecto de ellos la CIDH actúa

\footnotetext{
El corpus iuris internacional relativo a los derechos humanos está constituido por dos tipos de normas: (a) Las normas convencionales que forman parte de la llamada legislación intangible, entre las que se encuentran los pactos, tratados, convenciones, cartas y protocolos y cuya particularidad radica en su carácter vinculante para los Estados que son parte en ellas; y (b) un número muy elevado de otras normas como las declaraciones, principios, reglas, etc., las cuales no poseen los atributos juridicos de las normas anteriores pero cuentan con una fuerza politica persuasiva muy importante (Levin, 1999, p. 10).

4 Adoptada el 02 de mayo de 1948, siete meses antes de la adopción de la Declaración Universal.
} 
con base a dicho instrumento y a la Carta de la OEA (nivel de compromiso débil), como es el caso de Estados Unidos; (b) hay otros Estados que han ratificado la Convención Americana pero no han aceptado la competencia de la Corte IDH, por lo que la CIDH actúa en aplicación de la CADH (nivel de compromiso medio); y (c) hay ciertos Estados que han ratificado el Pacto de San José y también han aceptado la competencia de la Corte, por lo que sus actuaciones son objeto de vigilancia tanto por ésta como por la CIDH (nivel de compromiso fuerte), como es el caso de los países de Centroamérica y México.

Por tanto, Estados Unidos tiene un nivel de compromiso débil y sólo es objeto de vigilancia por parte de la $\mathrm{CIDH}$ en el marco de las disposiciones de la Declaración Americana. En este sentido, la CIDH está facultada para recibir y examinar denuncias que contengan presuntas violaciones de los derechos humanos contenidos en la Declaración Americana (art. 1 del Estatuto de la CIDH y art. 23 y 49 de su Reglamento) con respecto a Estados como Estados Unidos, que no han ratificado la Convención Americana.

Tanto la CIDH como la Corte IDH han jugado un papel fundamental en la promoción y protección de los derechos humanos en el continente, ya que regulan un procedimiento mediante el cual cualquier persona o grupo de personas, o entidad no gubernamental legalmente reconocida en uno o más Estados miembros de la OEA, puede presentar peticiones que contengan denuncias o quejas de violación de los instrumentos interamericanos por un Estado Parte. En tal sentido, constituyen una estructura doble de protección, pues por un lado, la $\mathrm{CIDH}$ recibe, tramita e investiga los hechos denunciados contra los Estados por violación de los derechos reconocidos, y por otro, la Corte IDH se encarga de emitir sentencias que determinan o no la responsabilidad internacional de los Estados por esas supuestas violaciones.

En esa línea, cada una de estas instancias regionales cuenta con varios mecanismos que les permiten llevar a cabo sus funciones de control. Ambos órganos cuentan con dos funciones esenciales, la función consultiva y la función contenciosa, las cuales juegan un papel fundamental de cara a la realización efectiva de los derechos humanos, ya que los Estados deben asegurar que todos sus órganos -jurisdiccionales, administrativos, etc.- conozcan y sigan el alcance de los lineamientos interpretativos desarrollados por la CIDH y la Corte IDH como intérpretes finales de los instrumentos interamericanos, ya que ignorarlos o desconocerlos puede provocar la responsabilidad internacional del Estado.

La función consultiva constituye una herramienta muy valiosa para la tutela de los derechos humanos, ya que a través de la emisión de informes temáticos o de país, opiniones consultivas, recomendaciones generales, etc., se ha permitido un análisis integral de la situación general de estos derechos, de una problemática específica en un determinado país o región, o del alcance y contenido de un derecho o norma interamericana, lo cual hace posible obtener una visión comprensiva y comparada "de los obstáculos y los pasos dados para garantizar el pleno goce de los derechos [lo cual ayuda] al desarrollo de soluciones regionales, entre otras cosas" (Krsticevic, 2004, p.150). Así, la Corte IDH ha emitido dos opiniones consultivas relacionadas con los derechos de los inmigrantes que constituyen herramientas importantes en la promoción y defensa de sus derechos (Corte Interamericana de Derechos Humanos [Corte IDH], 1999; 2003). 
Con respecto a la función contenciosa de ambos órganos, por un lado la $\mathrm{CIDH}$ (a) puede adoptar medidas preventivas o cautelares de protección en caso de gravedad y urgencia para evitar daños irreparables a las personas, solicitando al Estado que tome las medidas necesarias para prevenir la violación de los derechos humanos de las víctimas; por ejemplo, estableciendo un sistema de vigilancia nocturna en la casa de la persona agraviada, habilitando un número de teléfono de emergencia, brindando protección personal hasta que desaparezcan las causas del peligro, suspendiendo temporalmente una deportación, etc.; y a su vez, (b) puede recibir denuncias o peticiones individuales para determinar si existe o no la violación de un derecho reconocido y someter el asunto a conocimiento de la Corte IDH.

Cuando la $\mathrm{CIDH}$ recibe una denuncia o petición individual, primero le transmite al Estado las partes pertinentes de la misma para que pueda hacer sus observaciones; asimismo, puede solicitar a la parte denunciante que envíe información adicional relevante en caso de que sea necesario. Después de ello, la $\mathrm{CIDH}$ puede decretar la admisibilidad o inadmisibilidad de la denuncia, observando si se cumple con los requisitos formales para conocer del asunto. Una vez superada la fase de admisibilidad, se inicia lo que se conoce en el proceso como la "etapa de fondo", en la cual se analiza, con la información ofrecida por el Estado y la parte denunciante, la existencia de violaciones concretas. En este punto es importante resaltar que durante el proceso es permisible que la $\mathrm{CIDH}$ se ponga a disposición de las partes para que puedan llegar a una solución amistosa antes de emitir sus propias conclusiones y recomendaciones, o antes de llegar a soluciones más enérgicas (Corte IDH, 1994, párr. 27).

Si finalmente no se llega a una solución amistosa, la CIDH elabora dentro de un plazo de 3 meses un informe confidencial conocido como "Informe número 50" (art. 50 de la Convención Americana) en el que expone los hechos denunciados, sus conclusiones y observaciones, así como lo que hayan sostenido las partes en el procedimiento, y lo transmite al Estado con las recomendaciones que juzgue convenientes para que sean adoptadas por éste y se remedie la situación denunciada (arts. 48-51 de la Convención Americana).

Desde el momento en que el "Informe número 50" es transmitido al Estado, comienza a correr el plazo señalado, tiempo durante el cual la CIDH puede decidir someter el caso a la Corte IDH. Si bien esta decisión es una facultad discrecional de la $\mathrm{CIDH}$, la misma no puede ejercerse arbitrariamente e impidiendo que las víctimas obtengan un pronunciamiento del máximo tribunal sobre su petición (Corte IDH, 1993, párr. 50). Evidentemente, como Estados Unidos no es parte en la Convención Americana, la CIDH no puede someterle el caso para su conocimiento, sino que sólo puede publicar su decisión en un informe definitivo (conocido como "Informe número 51”) que contenga su opinión, conclusiones finales y recomendaciones. Este informe será transmitido a las partes, quienes presentarán, en el plazo fijado por la $\mathrm{CIDH}$, información sobre el cumplimiento de las recomendaciones. A su vez, podrá ser incluido en el Informe Anual a la Asamblea General de la OEA o publicado en cualquier otro medio que la CIDH considere apropiado.

Por su parte, la Corte IDH en el desempeño de su función contenciosa determina si un Estado que ha aceptado su competencia ha incurrido en responsabilidad internacional por haber violado alguno de los derechos consagrados 
en la Convención Americana o en otros instrumentos interamericanos que la facultan para ello, siendo sus sentencias obligatorias.

\section{El procedimiento ante la CIDH: ¿Una luz al final del túnel?}

La Declaración Americana reconoce una serie de derechos que, en el marco de los procedimientos de deportación, su observancia resulta fundamental para que los Estados cumplan con sus obligaciones internacionales en materia de derechos humanos, entre ellos, el derecho a la protección de la honra, la reputación familiar y la vida privada y familiar (art. V); el derecho a la constitución y a la protección de la familia (art. VI); el derecho de protección a la maternidad y a la infancia (art. VII); el derecho a recurrir a los tribunales para hacer valer sus derechos (art. XVIII); y el derecho a un proceso justo (art. XXVI).

A primera vista, parecería que en los procedimientos encaminados a determinar la deportación de Smith y Armendáriz, las autoridades estadounidenses no observaron las disposiciones de la Declaración Americana, en virtud de lo cual, las víctimas decidieron presentar una denuncia ante la CIDH. Así, el 27 de diciembre de 2002 y el 17 de julio de 2003, la CIDH recibió peticiones de varias organizaciones de derechos humanos en nombre de Wayne Smith y sus hijos, y Hugo Armendáriz y sus hijos, respectivamente, en las que denuncian a Estados Unidos por la violación de sus derechos a la vida, libertad y seguridad personal, a la vida privada y familiar, a la protección de la familia, a la protección a la maternidad y a la infancia, a la inviolabilidad del domicilio, a la justicia y a un proceso regular, contenidos en la Declaración Americana.

En términos generales, la denuncia establecía que Smith y Wayne fueron sujetos a deportación sin permitírseles presentar una defensa razonable en las cortes administrativa y judicial, incluidas las consideraciones humanitarias internacionalmente requeridas con respecto a las deportaciones, tales como, la duración del período de su residencia legal en Estados Unidos; sus vínculos familiares en este país; el potencial perjuicio de sus familiares que se quedan en Estados Unidos; los vínculos con sus países de origen; el alcance de la rehabilitación y contribución social a los Estados Unidos; cualquier consideración médica o psicológica y la gravedad de la ofensa cometida por ellos y su edad cuando la cometieron.

Como era de esperarse, Estados Unidos alegó que (a) de conformidad con el derecho internacional tiene la facultad de expulsar de su territorio a extranjeros criminales; (b) el marco legal establecido en sus leyes migratorias, particularmente la IIRIRA y la ADEPA es razonable y se ajusta a sus obligaciones internacionales; y (c) la interpretación que los denunciantes hacen de la Declaración Americana es demasiado amplia y no toma en cuenta el derecho de un Estado a tomar las acciones legales para proteger el bienestar general y la seguridad de otras personas que residen en su territorio (Comisión Interamericana de Derechos Humanos, 2010, párr. 31 43).

En su análisis, la CIDH consideró que si bien es cierto que de acuerdo 
al derecho internacional los Estados tienen la facultad de controlar el ingreso, residencia y expulsión de no ciudadanos, en los procedimientos de deportación "deben tener en cuenta ciertas protecciones que consagran valores fundamentales de las sociedades democráticas” (CIDH, 2008, párr. 78). En este sentido, toda política de inmigración "debe garantizar a todos una decisión individual con las garantías del debido proceso; debe respetar el derecho a la vida, a la integridad física y mental, familiar y el derecho de los niños a obtener medios especiales de protección” (CIDH, 2010, párr. 50; véase también CIDH, 2000).

Para la CIDH, debe existir una prueba de equilibrio en virtud de la cual se analice el interés legítimo del Estado de proteger y promover el bienestar general y los derechos fundamentales de los residentes no ciudadanos sujetos de deportación, tales como el derecho a la vida familiar y el mejor interés de sus hijos que podrían ser separados durante años por los procedimientos de deportación. En este sentido, la CIDH consideró que ni Wayne Smith ni Hugo Armendáriz tuvieron "una oportunidad de presentar una defensa humanitaria ante la deportación, ni se consideraron debidamente sus derechos de familia antes de ejecutar tal medida. Tampoco fueron tomados en cuenta los mejores intereses de sus respectivos hijos, ciudadanos estadounidenses, por parte de los funcionarios que tomaron las correspondientes decisiones" (CIDH, 2010, párr. 51, 57 y 59).

Por tanto, la CIDH estableció que en estos casos Estados Unidos violó los derechos fundamentales de Smith y Armendáriz consagrados por los artículos V, VI, VII, XVIII y XXVI de la Declaración Americana al no considerar debidamente de forma individual sus derechos a la vida familiar y los mejores intereses de sus hijos en los respectivos procedimientos de deportación, y al no ofrecerles "un mecanismo judicial para presentar sus defensas por razones humanitarias y ofrecer una reparación efectiva, si hubiera méritos, de preservar sus derechos fundamentales" (CIDH, 2010, párr. 60 y 64).

Bajo estos parámetros, la CIDH le recomendó a Estados Unidos (a) permitir a Wayne Smith y Hugo Armendáriz regresar a los Estados Unidos a expensas del Estado; (b) reabrir los procedimientos de inmigración respectivos de los denunciantes y permitirles presentar sus defensas por razones humanitarias en relación con su deportación de los Estados Unidos; (c) permitir que un juez de inmigración competente e independiente aplique una prueba de equilibrio a los casos individuales de los denunciantes, que considere debidamente sus defensas por razones humanitarias y pueda proveer una reparación significativa; y (d) implementar leyes para asegurar que los derechos a la vida familiar de los residentes no ciudadanos consagrados en la Declaración Americana, sean debidamente protegidos y gocen del debido proceso en los procedimientos sobre deportaciones (CIDH, 2010, párr. 67, numerales 1-4). 


\section{Paso a paso: de la victoria jurídica hacia el desafío de la victoria política}

Sin duda alguna, esta es una decisión histórica de la CIDH en tanto que coloca el fenómeno migratorio bajo el prisma de la dignidad humana y reafirma que "la calidad migratoria de una persona no puede constituir, de manera alguna, una justificación para privarla del goce y ejercicio de sus derechos humanos" (Corte CIDH, 2003, párr. 134).

De esta manera, los casos de Wayne Smith y Hugo Armendáriz demuestran la urgente necesidad de una reforma migratoria en los Estados Unidos que garantice el derecho al debido proceso legal en el marco de las garantías mínimas que se deben brindar a todo inmigrante, independientemente de su estatus migratorio, y que guarde un equilibrio entre los intereses estatales y la protección de los derechos humanos.

Si bien en el ejercicio de su facultad de fijar políticas migratorias, es lícito que Estados Unidos establezca medidas atinentes al ingreso, permanencia o salida voluntaria o forzada de inmigrantes, ello no le faculta a que tales medidas atenten contra la integridad, la vida familiar y el interés superior de las niñas y niños cuyos padres y madres son susceptibles de deportación, y que desde una concepción de los desechos humanos ya no son "útiles" para la nación y representan un peligro para la sociedad.

Por ello, la resolución de la CIDH constituye (a) un paso fundamental en la lucha por humanizar las decisiones estatales en materia de deportaciones; (b) una herramienta para que las organizaciones de inmigrantes y de defensa de sus derechos impulsen y fortalezcan sus acciones de incidencia en el cambio, elaboración e implementación de políticas migratorias estatales desde una concepción de los derechos humanos; y (c) un instrumento jurídico y político para que los Estados centroamericanos y mexicano exijan a su par estadounidense un trato respetuoso de los derechos humanos de sus ciudadanos que viven en Estados Unidos ${ }^{5}$.

\section{Referencias bibliográficas}

AOL Noticias. (2010). Deportaciones alcanzan niveles sin precedente en EEUU. Recuperado el 01 de octubre de 2010 de http://noticias.aol.com/2010/08/12/ deportaciones-eeuu/.

Barcellona, P. (1992). Postmodernidad y comunidad. El regreso de la vinculación social, Madrid: Editorial Trotta, Madrid.

Cançado Trindade, A. (2001). El Derecho Internacional de los Derechos Humanos en el siglo XXI. Santiago de Chile: Editorial Jurídica de Chile.

Chaudry, A., Capps, R., Pedroza, J. M., Castañeda, R. M., Santos, R. \& Scott, M. 
M. (2010, February). Facing Our Future: Children in the Aftermath of Inmigration Enforcement. Washington, D.C.: The Urban Institute.

Comisión de las Comunidades Europeas. (2005). Propuesta de Directiva del Parlamento Europeo y del Consejo relativa a procedimientos y normas comunes en los Estados miembros para el retorno de los nacionales de terceros países que se encuentren ilegalmente en su territorio. Recuperado el 01 de octubre de 2010 de http:// eur-lex.europa.eu/LexUriServ/LexUriServ.do?uri=COM:2005:0391:FIN:ES: PDF

Comisión Interamericana de Derechos Humanos. (2000, 28 de febrero). Informe sobre la situación de los derechos humanos de los solicitantes de asilo en el marco del sistema canadiense de determinación de la condición de refugiado. Recuperado el 02 de octubre de http://www.cidh.org/countryrep/Canada2000sp/canada. htm.

Comisión Interamericana de Derechos Humanos. (2008, 25 de julio). Caso Andrea Mortlock vs. Estados Unidos. Informe n 63/08. Caso n². 12.534. Recuperado el 02 de octubre de 2010 de http://www.cidh.org/annualrep/2008sp/ EEUU12534.sp.htm.

Comisión Interamericana de Derechos Humanos. (2010, 12 de julio). Caso Wayne Smith, Hugo Armendáriz y otros vs. Estados Unidos. Informe n 8118. Caso n ${ }^{\circ}$. 12.562. Recuperado el 02 de octubre de 2010 de http://www.acnur.org/ secciones/index.php?viewCat $=70$.

Comisión Interamericana de Derechos Humanos/ Organización de los Estados Americanos (2010, 12 de julio). Caso Wayne Smith, Hugo Armendáriz y otros vs. Estados Unidos. Informe No. 81/10. Caso n. 12.562, 12 de julio de 2010. Recuperado el 02 de octubre de 2010 de http://www.acnur.org/biblioteca/ pdf/7959.pdf

Corte Interamericana de Derechos Humanos. (1993, 16 de julio). Ciertas atribuciones de la Comisión Interamericana de Derechos Humanos (Arts. 41, 42, 46, 47, 50 y 51 de la Convención Americana sobre Derechos Humanos), Opinión Consultiva OC-13/93, del 16 de julio de 1993. Recuperado el 01 de octubre de 2010 de http://www.corteidh.or.cr/docs/opiniones/seriea_13_esp.pdf.

Corte Interamericana de Derechos Humanos. (1994, 21 de enero). Caso Caballero Delgado y Santana vs. Colombia. Excepciones preliminares, Sentencia de 21 de enero de 1994. Recuperado el 01 de octubre de 2010 de http://www.corteidh. or.cr/docs/casos/articulos/seriec_17_esp.pdf.

Corte Interamericana de Derechos Humanos. (1999, 01 de octubre). El Derecho a la información sobre la asistencia consular en el marco de las garantías del debido proceso legal, Opinión Consultiva OC-16/99. Recuperado el 01 de octubre de 2010 de http://www.corteidh.or.cr/opiniones.cfm.

Corte Interamericana de Derechos Humanos. (2003, 17 de septiembre). Condición jurídica y derechos de los migrantes indocumentados, Opinión Consultiva OC18/03. Recuperado el 01 de octubre de 2010 de http://www.corteidh.or.cr/ opiniones.cfm.

Human Rights Watch. (2009, April). Forced apart (By the numbers). Non-citizens deported mostly by nonviolent offences. New York: Human Rights Watch.

Krsticevic, V. (2004). La protección de los derechos económicos, sociales y culturales 
en el Sistema Interamericano. En Centro por la Justicia y el Derecho Internacional (Ed.), Construyendo una Agenda para la justiciabilidad de los derechos sociales. San José, Costa Rica: Publicaciones CEJIL.

Levin, L. (1999). Derechos humanos: preguntas y respuestas. Bilbao: Ediciones UNESCO/ Bakeaz.

Nair, S. (2006). Y vendrán... Las migraciones en tiempos hostiles. Barcelona: Planeta.

Rocha, J. L. (2008). Deportados: sin papeles, sin derechos y con fronteras. Envio, (320), noviembre. Recuperado el 01 de octubre de 2010 de http://www.envio. org.ni/articulo/3897. 